\title{
Exposure to Clothianidin Seed-Treated Canola Has No Long-Term Impact on Honey Bees
}

\author{
Author(s): G. Christopher Cutler and Cynthia D. Scott-Dupree
}

Source: Journal of Economic Entomology, 100(3):765-772. 2007.

Published By: Entomological Society of America

DOI: 10.1603/0022-0493(2007)100[765:ETCSCH]2.0.CO;2

URL:

http://www.bioone.org/doi/full/10.1603/0022-

0493\%282007\%29100\%5B765\%3AETCSCH\%5D2.0.CO\%3B2

BioOne (www.bioone.org) is an electronic aggregator of bioscience research content, and the online home to over 160 journals and books published by not-for-profit societies, associations, museums, institutions, and presses.

Your use of this PDF, the BioOne Web site, and all posted and associated content indicates your acceptance of BioOne's Terms of Use, available at www.bioone.org/page/terms_of_use.

Usage of BioOne content is strictly limited to personal, educational, and non-commercial use. Commercial inquiries or rights and permissions requests should be directed to the individual publisher as copyright holder. 


\title{
Exposure to Clothianidin Seed-Treated Canola Has No Long-Term Impact on Honey Bees
}

\author{
G. CHRISTOPHER CUTLER ${ }^{1}$ AND CYNTHIA D. SCOTT-DUPREE \\ Department of Environmental Biology, Ontario Agricultural College, University of Guelph, Guelph, \\ Ontario, Canada N1G 2W1
}

\begin{abstract}
J. Econ. Entomol. 100(3): 765-772 (2007)
ABSTRACT We conducted a long-term investigation to ascertain effects on honey bee, Apis mellifera L., colonies during and after exposure to flowering canola, Brassica napus variety Hyola 420, grown from clothianidin-treated seed. Colonies were placed in the middle of 1-ha clothianidin seed-treated or control canola fields for 3 wk during bloom, and thereafter they were moved to a fall apiary. There were four treated and four control fields, and four colonies per field, giving 32 colonies total. Bee mortality, worker longevity, and brood development were regularly assessed in each colony for $130 \mathrm{~d}$ from initial exposure to canola. Samples of honey, beeswax, pollen, and nectar were regularly collected for $130 \mathrm{~d}$, and the samples were analyzed for clothianidin residues by using high-performance liquid chromatography with tandem mass spectrometry detection. Overall, no differences in bee mortality, worker longevity, or brood development occurred between control and treatment groups throughout the study. Weight gains of and honey yields from colonies in treated fields were not significantly different from those in control fields. Although clothianidin residues were detected in honey, nectar, and pollen from colonies in clothianidin-treated fields, maximum concentrations detected were 8- to 22 -fold below the reported no observable adverse effects concentration. Clothianidin residues were not detected in any beeswax sample. Assessment of overwintered colonies in spring found no differences in those originally exposed to treated or control canola. The results show that honey bee colonies will, in the long-term, be unaffected by exposure to clothianidin seed-treated canola.
\end{abstract}

KEY WORDS honey bees, clothianidin, seed-treatment, canola, long-term assessment

Wild and domesticated bees are key components of many natural and artificial ecosystems. Most angiosperms would be unable to complete their development without the aid of pollinators, and it is estimated that three quarters of the leading global food crops require or benefit from pollination, primarily by bees (Roubik 1995, Michener 2000, Klein et al. 2007). Pollination by managed bees, particularly honey bees, Apis mellifera L., in agroecosystems is valued at $>$ US\$890 million in Canada (Canadian Honey Council 2005) and almost US $\$ 15$ billion in the United States (Morse and Calderone 2000). In addition, beekeeping with honey bees continues to be an important industry, generating hundreds of millions of dollars per year in North America through honey sales (Canadian Honey Council 2005, National Honey Board 2005), not to mention profits accrued from beeswax, pollen, and other hive products.

Although many agricultural crops serve as a rich source of required nectar and pollen, various agricul-

\footnotetext{
${ }^{1}$ Corresponding author: Current address: Faculty of Land and Food Systems, 2357 Main Mall, Vancouver, BC, Canada V6T 1Z4 (e-mail: gccutler@interchange.ubc.ca).
}

tural practices may be hazardous to pollinators. Pesticide exposure is regarded a potential threat to honey bees; as such, acute toxicity tests on honey bees are usually required before registration of pesticides in Canada and the United States. In an attempt to decrease environmental contamination and pesticide exposure in humans and nontarget organisms, "reducedrisk" insecticidal seed treatments-alternatives to foliar applied broad-spectrum insecticides-have been pursued. Low-rate systemic insecticides are applied to soil or directly to seeds at low concentrations, and they are subsequently distributed throughout plant tissues during development, providing prolonged protection from root and foliar pests, while avoiding repetitive foliar insecticide applications.

Probably the most successful class of reduced-risk systemic insecticides is the chloronicotinyl (syn. neonicotinoid) compounds, introduced in 1991 with registration of imidacloprid (Bayer CropScience, Monheim am Rhein, Germany) and followed by development of thiacloprid in 2000 (Bayer CropScience). Clothianidin is considered the third member of the chloronicotinyl class (Jeschke et al. 2003). The seed treatment formulation (Poncho, Bayer 
CropScience) has high root systemicity and insecticidal activity against a wide range of economically important insect pests of sugar beet (Beta vulgaris L.); corn, Zea mays L.; and oilseed crops (Ohkawara et al. 2002, Schwarz et al. 2002). However, there are concerns of potential adverse impacts of this class of insecticides on nontarget organisms. Of particular concern are potential risks to pollinators that may be exposed to chloronicotinyl residues in plant pollen and nectar, and the past decade has witnessed considerable debate over this impact on bees. Several reviews indicate that chronic exposure to concentrations of imidacloprid equivalent to those found in seed treatments pose negligible risks to honey bees (Schmuck et al. 2001, Maus et al. 2003, Schmuck 2004, Faucon et al. 2005). In laboratory studies, Kirchner (1999) found bees rejected imidacloprid-contaminated food at $20 \mathrm{ppb}$, and Decourtye et al. (2001) reported compromised learning in bees after exposures as low as $12-48 \mathrm{ppb}$. Although the majority of studies report no acute or chronic toxicity at imidacloprid exposures $\leq 20 \mathrm{ppb}$ (for review, see Maus et al. 2003), a controversial study by Suchail et al. (2001) found high chronic toxicity in honey bees fed low concentrations of imidacloprid.

Some laboratory and field investigations have evaluated potential effects of clothianidin on pollinators (C.D.S.-D. and M. S. Spivak, unpublished data; Franklin et al. 2004; Bailey et al. 2005; King 2005). However, no experiments have monitored honey bee colonies during and after exposure in the field. Here, we present results of a long-term study ascertaining impacts on honey bee colonies during and after exposure to canola grown from seed treated with the maximum recommended rate of clothianidin.

\section{Materials and Methods}

With exception of data collected during the spring colony assessment, this research was conducted in accordance with the Organization for Economic Cooperation Development Principles of Good Laboratory Practice (EPA 1989, OECD 1999).

Seed Treatment. Nongenetically transformed canola, Brassica napus variety Hyola 420 (Interstate Payco Seed Company, West Fargo, ND), was subjected to one of the following treatments: 1) clothianidintreated seed prepared with a seed-treatment slurry consisting of Prosper FL (9.64\% clothianidin, plus fungicides thiram, carboxin, and metalaxyl, Bayer CropScience) at 1,375.0 ml/ $100 \mathrm{~kg}$ seed, and Poncho $600 \mathrm{FS}$ ( $48.96 \%$ clothianidin, Bayer CropScience) at $458.7 \mathrm{ml} /$ $100 \mathrm{~kg}$ seed. This slurry delivered clothianidin at $400 \mathrm{~g}$ active ingredient (AI) /100 kg seed, the highest recommended rate for canola in Canada; or 2) control seed treated with a specially prepared Prosper FL "blank" formulation, delivering the same rate of fungicides and inert ingredients as the clothianidintreated seed, without clothianidin, and a specially prepared Poncho 600 FS blank formulation that also contained the inert ingredients but lacked clothianidin. Samples of clothianidin-treated and control seed were sent to ALS Environmental (Edmonton, Alberta, Canada) for verification of clothianidin content.

Canola Fields. Spring canola fields were established on the University of Guelph Elora Research Station, Elora, Ontario, Canada (two sites, E1 and E2) and on two farms owned by grower cooperators (two sites, W3 and W4) in proximity to the Elora Research Station. Each site consisted of two 1-ha fields, one field planted with clothianidin-treated seed and the other field planted with control seed, giving eight fields total. Fields at each site were separated by at least $295 \mathrm{~m}$, determined by global positioning system. Canola seeds were planted on $20-21$ May at a depth of $\approx 4 \mathrm{~cm}$ in a fine, firm seedbed at the highest recommended rate $(8.0 \mathrm{~kg} / \mathrm{ha})$ to ensure a high number of plants and ample forage for bees. Therefore, clothianidin was applied at $32 \mathrm{~g}$ (AI) / ha. A section of field E1C was not seeded properly during the initial planting and was replanted on 6 June. All fields received a preplant treatment with Treflan EC (Dow AgroSciences Canada Inc., Calgary, Alberta, Canada) and fertilizer according to Ontario canola production recommendations (OMAF 2004). Comprehensive ground-truthing determined that availability of alternative forage within $1 \mathrm{~km}$ of the colonies situated in canola fields was negligible. To our knowledge, no other flowering crops or corn grown from seed treated with clothianidin were planted within a $1-\mathrm{km}$ radius of our test fields.

Canola seedling emergence rates were determined on 3 and 7-8 June. On each date, the number of emerged plants per 1-m row in 10 randomly selected locations in each field was counted. Plant growth in each meter (all plants combined) was assessed and assigned a rank: 1, cotyledon; 2 , two true leaves; 3 , three true leaves; 4 , four true leaves; and 5 , five true leaves. Crucifer flea beetle, Phyllotreta cruciferae Goeze, and striped flea beetle, Phyllotreta striolata (F.), damage in each meter of plants also was assessed by rank: 0 , no damage; 1 , up to $25 \%$ damage; 2 , up to $50 \%$ damage; 3 , up to $75 \%$ damage; and $4,100 \%$ damage.

Colony Establishment, Maintenance, and Transport. Before placement in canola, test colonies $(n=$ 32 ) were held at a spring apiary near the Townsend House Bee Research Facility (THBRF) at the University of Guelph. Test colonies had successfully overwintered, and they were headed by naturally mated queens of the same lineage and approximately the same age. Throughout the study, queen cells were destroyed whenever found to prevent swarming. At initiation of the experiment each colony consisted of a single brood chamber $(24 \mathrm{~cm}$ in depth, 10 frames per super), below a shallow honey super $(16.5 \mathrm{~cm}$ in depth, nine frames per super). An Ontario Agricultural College (OAC) pollen trap (Smith 1963) was fitted above the bottom board of each colony. All moveable components of each colony (e.g., brood chambers, supers, covers) were labeled to ensure accurate cross-referencing. In spring, all colonies received three 30-g dustings of a 5:1 icing sugar/ oxytetracycline (Terramycin 25, Pfizer Inc., New York, NY) mixture at 1-wk intervals to protect against American 
foulbrood, and a coumopheos (CheckMite, Bayer Inc., Toronto, Ontario, Canada) treatment for control of varroa mite, Varroa destructor Anderson \& Trueman. Throughout the study, incidence of varroa mite and chalkbrood was very low (management for these pests was not warranted), and tracheal mite, Acarapis woodi Rennie, American foulbrood, and European foulbrood were never detected. Two days before transport to canola fields, test colonies were equalized by swapping frames, where necessary, to ensure that each had similar quantities of food stores, brood, and adults.

A 10- by 5-m clearing was mowed in the middle of each 1-ha canola field to accommodate four colonies. The central clearing was accessed by a 3-m-wide laneway. When $\approx 25-66 \%$ of canola blooms in fields had opened, four colonies were moved at night into each field. On 30 June, all 32 colonies were in the eight canola fields, and this date was identified as Day 0 . Colonies remained in fields the duration of bloom. On the night of $20-21$ July (Day 21 ), when $\approx 10-20 \%$ bloom remained in each field, colonies were moved to a fall apiary $\approx 35 \mathrm{~km}$ away at the former University of Guelph Cambridge Research Station, where they remained until termination of the study. At the fall apiary, colonies from control $(n=16)$ and clothianidin-treated $(n=16)$ fields were separated by at least $30 \mathrm{~m}$. No other colonies were present in this apiary.

Colony Assessments. Colony Weight Gain and Honey Yield. Colonies were weighed on day -1 and day 21 during transport to and from fields by using a scale attached to an Ezyloader 300MH boom (Ezyloader, Ballina, New South Wales, Australia) mounted on a flatbed truck used to move colonies. Honey yield per colony was determined by weighing empty honey supers before placement on and after removal from colonies. Honey supers were removed from and added to colonies as needed. A full super weight upon removal from a colony minus the empty super weight before placement on a colony gave the honey yield for that honey super. The sum of all honey super yields for a given colony equaled the total honey yield for that colony.

Adult Mortality. Colony adult mortality was assessed using a Gary dead bee trap (DBT) (Gary 1960) or a 1- by $2-\mathrm{m}$ white sheet placed on the ground extending out from the hive entrance (Faucon et al. 2005). One randomly selected colony at each field was fitted with a DBT, whereas the entrance sheet method was used for the remaining three (eight DBT and 24 entrance sheets total for the experiment). Dead workers and drones were collected from DBT or entrance sheets and counted approximately every $7 \mathrm{~d}$ from Day 0 to Day 130. Collected dead bees were disposed of after counting and sorting.

Brood. Area of sealed brood was estimated using a template brood frame that had the comb foundation removed, and, using rigid plastic stripping, was divided into six quadrants, each $\approx 10$ by $14 \mathrm{~cm}$. The template was laid over each frame of brood, and the percentage of sealed brood in each quadrant was estimated. This was done on both sides of each frame, for all 10 brood chamber frames in each colony. Percentage estimates were thereafter converted to square centimeters and summed to determine the total area of sealed brood per colony. To minimize variability in estimates, preliminary standardization of estimates was conducted, and the same two personnel conducted brood assessments throughout the entire study. Brood assessments were done approximately every $14 \mathrm{~d}$ up to Day 98 (6 October), after which time brood production had ceased.

Worker Longevity. Spare colonies, initiated from queens of the same lineage and approximately the same age as those in test colonies, were maintained at the THBRF. On Day 3, frames containing sealed cells ready for eclosion were removed from these spare colonies and placed in an on-site incubator $\left(32 \pm 3^{\circ} \mathrm{C}\right.$ and $60 \pm 5 \% \mathrm{RH}$ ) overnight. The next morning, 1,600 newly eclosed workers were marked with Opalith colored/numbered thoracic tags (Graze Bienenzuchtgeräte, Weinstadt, Germany) and placed in 12by 10 - by $5-\mathrm{cm}$ screened cages with a water source. Fifty tagged workers were added to each cage. On Day 4 , workers from each cage were introduced into one of the 32 test colonies. At each site, different-colored tagged workers were introduced to each of the four colonies. Because most tagged workers from the initial introduction were no longer recovered by Day 60, a second cohort of 50 tagged workers was added to each colony on Day 70. Tag colors and numbers of the second cohort were different from those of the initial introduction. After the second introduction, those from the first introduction were disregarded during data collection. Tagged workers were counted and recorded on $\approx 14$-d intervals during each brood assessment.

Spring Colony Assessment. Colonies were prepared for overwintering at the fall apiary in late October 2005 . Each colony was administered $\approx 30 \mathrm{~g}$ of a $5: 1$ icing sugar/oxytetracyline mixture. Colonies were "barrel fed" by providing 150 liters of sugar solution, consisting of 2:1 sucrose/water, in a 170-liter barrel. The top of the barrel was filled with straw, and the lid was left partially open to allow bees access to the sugar solution. In mid-November, colony entrances were reduced, an upper entrance was provided, and insulation was placed between the inner cover and the colony lid. Colonies were not wrapped with insulation as the fall apiary was very sheltered. Because of minimal mite infestation during the summer, no autumn varroa mite treatments were necessary. On 19-20 April 2006, the status of overwintered colonies was assessed. For each colony, the following data were collected: presence or absence of a healthy queen, presence or absence of eggs and larvae, area of sealed brood (methods described above), number of frames per colony containing adult workers, and a rank of overall health based on adult numbers (0, dead, no adults; 1 , weak, $\leq 4$ frames of adults; and 2 , healthy, $>4$ frames of adults) and a collective assessment of all data per colony.

Sample Collection and Residue Analysis. Nectar, honey, pollen, and beeswax samples were collected from test colonies on $\approx 14$-d intervals and subse- 
quently analyzed for clothianidin residues. Nectar samples were collected by gently shaking a randomly selected brood frame, containing stored uncapped nectar, over a sheet of waxed paper placed on a flat surface. Deposited nectar was then poured off the wax paper into brown glass jars. Honey from each colony was collected from randomly selected capped cells on honey super frames by using disposable plastic spatulas and stored in brown glass jars. Randomly selected samples of brood and food-free beeswax were collected from honey super frames of each colony by using disposable spatulas and placed in sealable freezer bags. Pollen was collected from each colony by using an OAC pollen trap (Smith 1963). Traps were activated $\approx 24 \mathrm{~h}$ before pollen collection, after which time pollen was transferred to brown glass jars by using disposable spatulas. Pollen traps were deactivated after collection. Samples from colonies were pooled at each field ( $n=8$ per collection day) such that $\approx 5 \mathrm{~g}$ each of nectar and honey, $3 \mathrm{~cm}^{2}$ of beeswax, and $10 \mathrm{~g}$ of pollen were collected on each sampling day. Samples were placed in a cooler with icepacks, returned to the University of Guelph, and stored at $-20^{\circ} \mathrm{C}$. Frozen samples were packed in dry ice in polystyrene foam boxes and sent by overnight courier to ALS Environmental for residue analysis.

Clothianidin-treated seed was dispersed, shaken, and sonicated in acetonitrile. A sample of the solution was diluted with acetonitrile in water and analyzed for the target analyte. Honey and nectar samples were each extracted by polytron blending in water and methanol, evaporated to aqueous and eluted through a Chem-Elut CE 1020 column (Varian, Palo Alto, CA). The resulting extract was evaporated to dryness, dissolved in acetonitrile/water with sonication, and finally transferred to an autosampler vial for analysis. Pollen samples were extracted using a modified method of that used for honey and nectar, and they were passed through a silica gel clean-up column. Beeswax samples were extracted in dichloromethane, potassium hydroxide, and concentrated phosphoric acid, and then they were evaporated. The dry beeswax residue was dissolved in methanol. All analyses were conducted by high-performance liquid chromatography-electronspray ionization tandem mass spectrometry. The limit of quantification of all analyses was 0.5 ppb.

Data Analysis. Canola plant emergence, colony weight gain, and honey yield data were analyzed using a standard least squares linear model (SAS Institute 2006), incorporating treatment and site as model effects. Canola plant development and flea beetle damage data were analyzed by logistic regression (SAS Institute 2006). Adult honey bee mortality, area of sealed brood per colony, and worker longevity data were analyzed by a standard least squares linear mixed model of repeated measures incorporating restricted maximum likelihood (REML) estimations and the Kenward-Roger correction (SAS Institute 2006). In mixed models, site and colony were considered random effects, and treatment and time (repeated measure) were fixed effects. For analysis of brood assess- ment and dead bee data, sampler and dead bee trapping method (entrance sheet or DBT), respectively, were added to the models as additional fixed effects. For spring colony assessment data, amount of sealed brood in colonies from control and clothianidin-treated fields was compared by $t$-test (SAS Institute 2006). A Wilcoxon test compared the number of frames of spring adult workers in control and treated colonies (SAS Institute 2006). All tests were conducted at $\alpha=0.05$.

\section{Results}

Canola Emergence. Although emergence was greater in clothianidin-treated fields than control fields on 3 June $(F=9.49, \mathrm{df}=1, P=0.0029)$, no difference was observed by 8 June $(F=2.24$, $\mathrm{df}=1$, $P=0.14)$. Emergence differed at sites on 3 June $(F=$ $7.70, \mathrm{df}=3, P=0.0002)$ and 8 June $(F=5.50, \mathrm{df}=3$, $P=0.0018$ ), being greatest at $\mathrm{E} 2$ and lowest at $\mathrm{W} 4$ on both sampling days. On both sampling days, a significant site $\times$ treatment interaction was found for emergence ( 3 June: $F=3.29, \mathrm{df}=3, P=0.026$; and 8 June: $F=5.24, \mathrm{df}=3, P=0.0025)$. Early development of emerged plants did not differ with treatment (3 June: $\chi^{2}=1.37, \mathrm{df}=1, P=0.24 ;$ and 8 June: $\chi^{2}=0.01, \mathrm{df}=$ $1, P=0.90$ ) or site (3 June: $\chi^{2}=1.75, \mathrm{df}=3, P=0.63$ and 8 June: $\left.\chi^{2}=6.70, \mathrm{df}=3, P=0.082\right)$, and there was no significant interaction of those effects ( 3 June: $\chi^{2}=$ $\left.1.75, \mathrm{df}=3, P=0.63 ; 8 \mathrm{June}: \chi^{2}=2.39, \mathrm{df}=3, P=0.50\right)$. Flea beetle damage, however, was significantly greater in control fields on both 3 June $\left(\chi^{2}=19.86, \mathrm{df}=1, P<\right.$ $0.0001)$ and 8 June $\left(\chi^{2}=18.88, \mathrm{df}=1, P<0.0001\right)$. Although flea beetle damage did not vary with site on 3 June $\left(\chi^{2}=6.70, \mathrm{df}=3, P=0.082\right)$, a difference between sites was found on 8 June $\left(\chi^{2}=10.55\right.$, $\mathrm{df}=$ $3, P=0.014)$. In general, we found plant vigor was qualitatively less in control fields than in clothianidintreated fields while colonies were in canola fields.

Colony Assessments. Colony Weight Gain and Honey Yield. There was no significant difference in weight gain of colonies from control and clothianidin-treated fields $(F=0.14, \mathrm{df}=1, P=0.70)$. In both treatments, colony weights increased $\approx 24 \mathrm{~kg}$ while in canola fields (Fig. 1). Differences in colony weight gain were not significant among sites $(F=2.81, \mathrm{df}=3, P=0.061)$, and there was no significant treatment $X$ site interaction $(F=1.02, \mathrm{df}=3, P=0.40)$. There was also no significant difference in colony honey yield from control and clothianidin-treated fields $(F=0.02, \mathrm{df}=1$, $P=0.89)$. Approximately $45 \mathrm{~kg}$ of honey per colony was harvested over the $130 \mathrm{~d}$ of the experiment (Fig. $1)$. Differences in honey yield were not significant among sites $(F=0.45$, $\mathrm{df}=3, P=0.72)$, and there was no significant treatment $\times$ site interaction for honey yield $(F=1.22, \mathrm{df}=3, P=0.33)$.

Adult Mortality. Although entrance sheets resulted in no technical difficulties or inadequate data, the operation of DBT was occasionally unreliable during the experiment. For example, traps were sometimes found partially open or loose from the colony, or were partially filled with water after rainfall events, thereby 


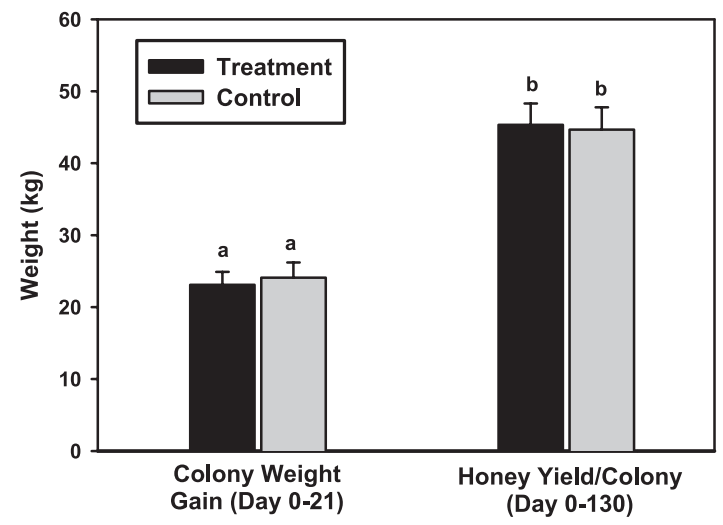

Fig. 1. Mean \pm SEM honey bee colony weight gain and honey yield after exposure to clothianidin-treated and control canola fields. Colonies were in canola fields for $21 \mathrm{~d}$ during bloom (Day 0-21), and thereafter they were moved to a fall apiary, $\approx 35 \mathrm{~km}$ away, where they were maintained for another $109 \mathrm{~d}$.

negating mortality data for associated colonies on those collection dates. On dates where there were less than three treated and three control colonies containing DBT with usable data, analyses comparing dead bee recovery methods were not done. In total, $n=18$ collection dates incorporated entrance sheet dead bee collection data, whereas $n=15$ collection dates incorporated DBT collection data.

The number of dead workers collected per colony was not affected by clothianidin treatment $(F=0.88$, $\mathrm{df}=1, P=0.36)$ or the interaction of treatment with Day $(F=0.85, \mathrm{df}=1, P=0.36)$. There were, however, significant changes over time in number of dead workers recovered from colonies $(F=41.20, \mathrm{df}=1, P<$ 0.001 ), and more dead workers were recovered with DBT than entrance sheets $(F=65.83$, df $=1, P<$ $0.001)$ (Fig. 2). Dead drone collections also were not affected by clothianidin treatment $(F=2.65, \mathrm{df}=1$, $P=0.17)$ or the interaction of treatment with Day $(F=2.06, \mathrm{df}=1, P=0.15)$. As with worker collections, number of dead drones collected per week changed over time $(F=6.24, \mathrm{df}=1, P=0.013)$, but there was no difference whether dead drones were collected with DBT or entrance sheets $(F=1.35, \mathrm{df}=1, P=$ $0.26)$. More dead workers than drones were recovered throughout the experiment, and worker and drone mortality increased in autumn (e.g., Day 99) as colonies prepared for overwintering (Fig. 2).

Brood. Brood assessments were conducted up to Day 97/98 (Fig. 3), after which time there was no or minimal sealed brood in colonies as they prepared for overwintering. Area of sealed brood per colony was not influenced by treatment $(F=1.01$, df $=1, P=$ $0.50)$, sampler $(F=4.68, \mathrm{df}=1, P=0.09)$, or the interaction of these factors $(F=2.32, \mathrm{df}=1, P=0.14)$. The amount of sealed brood did change significantly over time $(F=37.12, \mathrm{df}=1, P=0.001)$ but decreased sharply only by Day 97 (Fig. 3). There was no Day $X$ sampler $(F=0.001, \mathrm{df}=1, P=0.97)$ or Day $\times$ treatment $(F=1.32, \mathrm{df}=1, P=0.26)$ interaction.

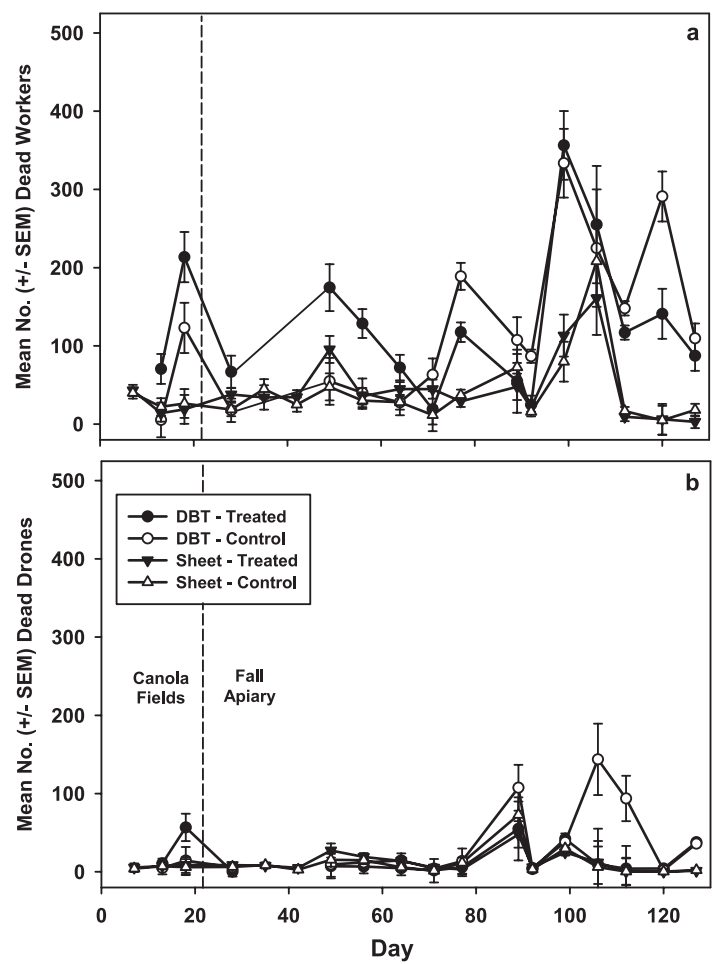

Fig. 2. Mean \pm SEM honey bee worker (a) and drone (b) mortality in colonies exposed to clothianidin-treated and control canola fields. Each of four sites (one treated, one control field per site) were provided with four colonies, three equipped with a white entrance sheet to identify dead workers and one colony fitted with a DBT. Colonies were in canola fields the first $21 \mathrm{~d}$ of the experiment, and thereafter they were moved to a fall apiary until $130 \mathrm{~d}$ from initial exposure to canola.

Worker Longevity. The number of tagged workers decreased over time in colonies from both clothianidin-treated and control canola fields $(F=58.69, \mathrm{df}=$ $14, P<0.0001$ ) (Fig. 4). However, there was no sig-

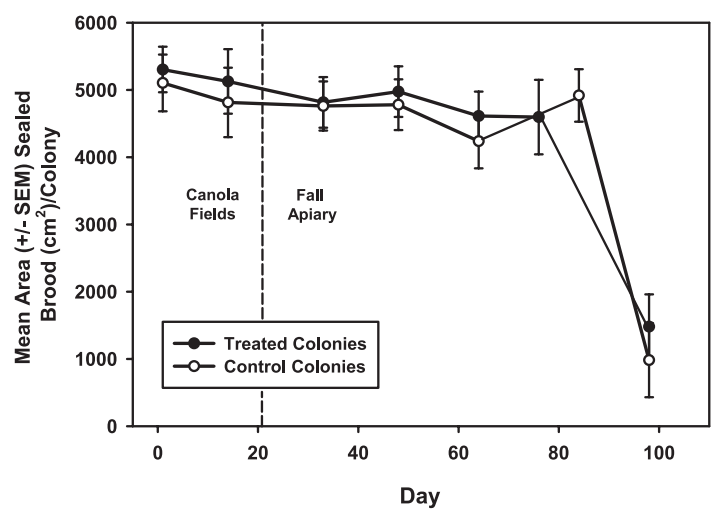

Fig. 3. Mean area \pm SEM of sealed brood in honey bee colonies in clothianidin-treated and control canola fields. Colonies were in canola fields the first $21 \mathrm{~d}$ of the experiment, and thereafter they were moved to a fall apiary until $130 \mathrm{~d}$ from initial exposure to canola. 


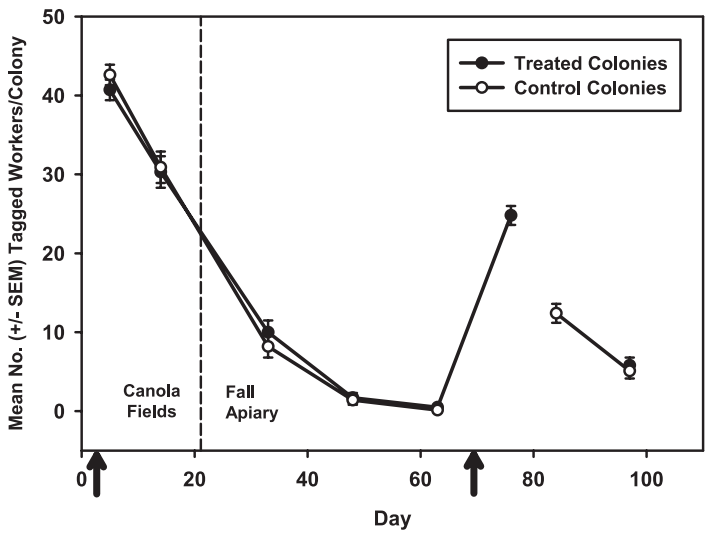

Fig. 4. Mean \pm SEM honey bee worker longevity in colonies in clothianidin-treated and control canola fields. Fifty workers tagged with colored/numbered thoracic tags were added to each colony (denoted by arrows on $\mathrm{x}$-axis) on Day 4 and again on Day 70. Colonies were in canola fields the first $21 \mathrm{~d}$ of the experiment and thereafter moved to a fall apiary until $130 \mathrm{~d}$ from initial exposure to canola. Tagged workers in each colony were counted approximately every 14 d except on Day 76/ 77 and Day 84 for control and clothianidin-treated colonies, respectively.

nificant effect of treatment on longevity of tagged workers $(F=0.06, \mathrm{df}=1, P=0.81)$, and there was no treatment $\times$ Day interaction $(F=0.51, \mathrm{df}=14, P=$ 0.76 ).

Spring Colony Assessment. There was no difference in health of colonies in spring 2006, whether they were originally in clothianidin seed-treated or control fields. Of the initial 32 colonies, two colonies from control fields and another colony from a treated field were classified dead at the end of autumn 2005 data collection, and these colonies were omitted from the spring assessment. These colonies lost their queen late in the fall, and they were unable to replace her before onset of winter. Of the remaining 29 colonies, only two colonies from clothianidin-treated fields and two colonies from control fields did not survive winter, and they were classified dead in spring. Of the 25 colonies that survived winter, all were queen-right (contained a healthy queen). There was no difference between control and clothianidin-treated colonies in amount of sealed brood $(F=0.35, \mathrm{df}=24, P=0.56)$ or in the number of frames of workers $\left(\chi^{2}=0.35, \mathrm{df}=5, P=\right.$ $0.95)$. Collectively, 24 colonies were classified healthy, one colony was weak, and four colonies were dead.

Residue Analysis. Clothianidin was detected in clothianidin-treated seed within acceptable limits of the prescribed rate (mean 4,175 ppm or $417 \mathrm{~g}$ clothianidin/100 kg seed). Clothianidin was not detected in seed treated with Prosper and Poncho blank formulations.

Control substance recovery of clothianidin residues from spiked honey, nectar, pollen, and beeswax samples was within acceptable limits, with in-phase recoveries (percentage \pm SD) of $93 \pm 13.0,89 \pm 13.3$, $87 \pm 13.8$, and $104 \pm 21.6$, respectively. The majority of samples collected had no quantifiable clothianidin residues $(<0.5 \mathrm{ppb})$, whether from colonies in clothianidin-treated or control fields. The maximum concentration of clothianidin detected in any sample of honey, nectar, pollen, and beeswax was 0.93, 2.24, 2.59, and $<0.5 \mathrm{ppb}$, respectively. Clothianidin was detected in one sample after colonies were moved to the fall apiary (nectar, field W3C, Day 42). Although clothianidin residues were absent from honey, pollen, and beeswax samples collected from colonies in control fields, initial analyses detected residues in three nectar samples from control colonies (field E1C, Day 7, 0.54 ppb; field W3C, Day 7, $0.67 \mathrm{ppb}$; and field W3C, Day $42,0.97 \mathrm{ppb}$ ). Subsequent analyses of backup nectar samples detected residues in two control colonies (field E1C, Day 7, 0.69 ppb; and field W3C, Day 7, 0.92 $\mathrm{ppb})$.

\section{Discussion}

Both pollination by bees and pesticide treatments are essential components of modern agriculture. Unfortunately, these two elements of agroecosystems are sometimes incompatible, with bees and the beekeeping industry having sustained losses through pesticide poisoning. Although use of systemic insecticide seed treatments is generally regarded a more ecologically sound alternative to foliar insecticide applications, systemic insecticides may be translocated to pollen or nectar during development of the seed-treated crop, meaning pollinators foraging on these plants could be exposed to toxin. Concerns of adverse effects of imidacloprid seed treatments on pollinators has been a subject of much debate (Schmuck et al. 2001, Maus et al. 2003, Faucon et al. 2005), but our knowledge of potential impacts of clothianidin, a new chloronicotinyl insecticide, on pollinators is minimal.

In the current study we attempted to use a realistic, worst-case scenario for honey bee exposure to clothianidin seed-treated canola. Seed was successfully treated with clothianidin at the highest recommended commercial rate for Canada and planted at a high seeding rate in 1-ha fields, ensuring ample forage for worker bees. Honey bee colonies were placed in the middle of canola fields during the bloom period, ensuring maximum exposure, and then they were moved to a fall apiary near bloom end. Little alternative forage was available to workers while in canola fields, and workers actively foraged on the canola. To assess potential long-term impacts, data were collected intensely over $130 \mathrm{~d}$ during summer and fall, and again in the spring.

Overall, we found no differences between colonies from clothianidin-treated and control fields. Colonies in clothianidin-treated fields gained as much weight and yielded as much honey as those in control fields. Mean honey yield per colony in the clothianidintreated colonies was comparable to the 2005 Ontario honey yield average of $46.6 \mathrm{~kg}$ (Mailvaganam 2005). Had honey production in our colonies started earlier (honey production typically begins mid-May in southern Ontario), our honey yields would probably have been much higher. In addition, assessment of colonies 
in the spring revealed no differences in brood production, number of adult workers, overwinter colony survival and overall colony health, whether colonies were originally in clothianidin seed-treated or control fields. Only $14 \%$ of colonies alive in autumn did not survive winter, and half of those colonies were control colonies; overwinter colony losses of $15 \%$ are not unusual in southern Ontario (P. Kelly, personal communication). Above all other factors, beekeepers would probably consider honey yield and overwinter mortality the most basic and yet most important measures of colony health.

Field exposure to clothianidin seed-treated canola caused no reduction in brood production or worker longevity. These results are consistent with those of other studies. In microcolonies consisting of $\approx 500$ worker bees, no effects on bee mortality or behavior, or colony development were detected after long-term exposure to clothianidin residues of up to $20 \mathrm{ppb}$ in pollen and nectar (Schmuck and Keppler 2003). In laboratory experiments with the bumble bee, Bombus impatiens Cresson, Franklin et al. (2004) showed that oral exposures as high as $36 \mathrm{ppb}$ clothianidin in pollensucrose diet had no effect on brood production, and adult worker, male, and queen production. Worker weights and foraging ability were also unaffected. In unpublished field experiment, C.D.S.-D. and M. S. Spivak (unpublished data) found no adverse effects on honey bees during $25 \mathrm{~d}$ in clothianidin seed-treated canola. Although Bailey et al. (2005) and King (2005) found that technical grade clothianidin was highly toxic to adult honey bees, and bumble bees (Bombus spp.), and leafcutter bees, Megachile rotundata $\mathrm{F}$., respectively, by direct contact, formulated product was nontoxic to honey bees through residual contact or ingestion of treated sweet corn pollen collected from the field (Bailey et al. 2005).

Except in autumn when adult mortality expectedly increased as colonies prepared for overwintering, dead worker collections rarely exceeded 200 individuals per colony per week and overall no differences in worker mortality between treatment and control colonies were detected. There was often discrepancy between numbers of dead bees collected with DBT and entrance sheets, although we suspect this may have been partially due to high artificial mortality with DBT. Similarly, Illies et al. (2002) found the original version of the Gary DBT resulted in artificially high estimates of mortality and a modified Gary DBT also had a negative effect on undertaking behavior (removal of dead bees from a colony by worker bees). Entrance sheets are disadvantageous in that they may not capture all dead bees removed from colonies, but use of larger entrance sheets could reduce this problem. Losses because of scavengers and wind have also been suggested drawbacks, although placement of colonies in the middle of the canola fields probably reduced exposure to both of these elements. Compared with DBT, which presented mechanistic and logistical challenges, the entrance sheet method provided a cheap, noninvasive method to assess bee mortality. Indeed, to a beekeeper the most obvious sign of pes- ticide poisoning is the presence of an exceptional number of dead bees in front of hives (Akratanakul 1990).

Clothianidin residues were detected in some pollen, nectar and honey samples from colonies that were in clothianidin-treated fields, although most samples had no detectable clothianidin residues. The maximum concentration of clothianidin detected in any sample was $2.59 \mathrm{ppb}$ (pollen), in-line with residue levels reported by C.D.S.-D. and M. S. Spivak (unpublished data), who found maximum concentrations of 3.0 and $3.7 \mathrm{ppb}$ in pollen and nectar, respectively, from clothianidin seed-treated canola. Considering that residue levels detected in this study were about eight-fold below the reported no observable adverse effects concentration (NOAEC) of $20 \mathrm{ppb}$ (Schmuck and Keppler 2003), derived from feeding experiments using spiked diets, clothianidin seed-treated canola seems to provides a favorable margin of safety for honey bees. Clothianidin was detected in only one sample after colonies were moved to the fall apiary, also suggesting that potential in-hive exposure is reduced after the bloom period. Although residues were not detected in honey, pollen and beeswax from colonies in control fields, clothianidin was detected in nectar from some colonies in control fields indicating that workers in these colonies foraged on clothianidintreated canola. The high seeding rate and relatively large area of canola fields likely retained most workers within their designated field, but separation between some control and treated fields may have been insufficient. Also, forage in some control fields was of lower quality (because of insect damage or problems during planting), which may have lured workers from control fields to higher quality forage in treated fields.

Semifield and field studies indicate that imidacloprid seed treatments pose negligible risk to pollinators (for review, see Maus et al. 2003), and it has been hypothesized that clothianidin offers an increased margin of safety to bees compared with imidacloprid (Franklin et al. 2004). Our results show that honey bees foraging on clothianidin seed-treated canola for up to $21 \mathrm{~d}$ can be exposed to clothianidin residues in pollen, nectar, and honey. However, exposure concentrations were well below those reportedly required to elicit toxic effects. Under the worst-case field scenario we attempted to use, no differences between colonies exposed to clothianidin seed-treated or control canola were found in terms of bee mortality or longevity, brood development, honey yield and overwinter survival. Field exposure to clothianidin seedtreated canola presents negligible risk to honey bees.

\section{Acknowledgments}

We thank T. Welsh, J. Sproule, C. Lafreniere, P. Kelly, and J. Bestari for technical assistance; P. MacFadden-Bates and R. Reichert (Bayer CropScience, Raleigh, NC) for preparing seed-treatments, and N. McLean (ALS Environmental) for conducting residue analysis. We thank C. R. Harris for review of the early draft of the manuscript. 


\section{References Cited}

Akratanakul, P. 1990. Beekeeping in Asia. FAO Agric. Serv. Bull. 68/4. Food and Agriculture Organisation of the United Nations, Rome, Italy.

Bailey, J., C. Scott-Dupree, R. Harris, J. Tolman, and B. Harris. 2005. Contact and oral toxicity to honey bees (Apis mellifera) of agents registered for use for sweet corn insect control in Ontario, Canada. Apidologie 36: $1-11$.

Canadian Honey Council. 2005. Overview of honey industry in Canada. Canadian Honey Council. (http://www. honeycouncil.ca/users/folder.asp?FolderID $=4558$ ).

Decourtye, A., M. Le Metayer, H. Pottiau, M. Tisseur, J. F. Odoux, and M. H. Pham-Delegue. 2001. Impairment of olfactory learning performances in the honey bee after long term ingestion of imidacloprid, pp. 113-117. In L. P. Belzunces, C. Pelissier and G. B. Lewis [eds.], Hazards of pesticides to Bees. Institut National de la Recherche Agronomique, Paris, France.

[EPA] Environmental Protection Agency. 1989. U.S. Environmental Protection Agency, Good Laboratory Practice Standards, 40 CFR Part 160 PP-300165A; FRL-3518-2, RIN 2070-AB68, Federal Insecticide, Fungicide and Rodenticide Act (FIFRA), 16 October 1989. Washington, DC.

Faucon, J. P., C. Aurieres, P. Drajnudel, M. Ribiere, A. C. Martel, S. Zeggane, M. P. Chauzat, and M.F.A. Aubert. 2005. Experimental study on the toxicity of imidacloprid given in syrup to honey bees (Apis mellifera). Pest Manag. Sci. 61: 111-125.

Franklin, M. T., M. L. Winston, and L. A. Morandin. 2004. Effects of clothianidin on Bombus impatiens (Hymenoptera: Apidae) colony health and foraging ability. J. Econ. Entomol. 97: 369-373.

Gary, N. E. 1960. A trap to quantitatively recover dead and abnormal bees from the hive. J. Econ. Entomol. 53: 782 785 .

Illies, I., W. Muehlen, G. Ducker, and N. Sachser. 2002. The influence of different bee traps on undertaking behaviour of the honey bee (Apis mellifera) and development of a new trap. Apidologie 33: 315-326.

Jeschke, P., H. Uneme, J. Benet-Bucholz, J. Stolting, W. Sirges, M. E. Beck, and W. Etzel. 2003. Clothianidin (TI435): the third member of the chloronicotinyl (CNI) family. Pflanzenschutz.-Nachr. Bayer 56: 5-25.

King, A. G. 2005. Impacts of agricultural practices and pest control agents on wild bees in spring canola. M.S. thesis, Department of Environmental Biology, University of Guelph, Guelph, Ontario, Canada.

Kirchner,W.H. 1999. Mad-bee disease? Sublethal effects of imidacloprid (Gaucho) on the behavior of honey bees. Association of Institutes of Bee Res., 50 Year Anniversary 1949-1999, reports of the 46th seminar in Marburg, 23-25 March 1998. Apidologie 30: 422-423.

Klein, A.-M., B. E. Vaissière, J. H. Cane, I. Steffan-Dewenter, S. A. Cunningham, C. Kremen, and T. Tscharntke. 2007. Importance of pollinators in changing landscapes for world crops. Proc. R. Soc. B Biol. Sci. 274: 303-313.
Mailvaganam, S. 2005. Estimated number of beekeepers, colonies of bees, production and value of honey, Ontario, 1982 to 2005. Ontario Ministry of Agriculture, Food and Rural Affairs. (http://www.omafra.gov.on.ca/english/ stats/hort/honey.html).

Maus, C., G. Cure, and R. Schmuck. 2003. Safety of imidacloprid seed dressings to honey bees: a comprehensive overview and compilation of the current state of knowledge. Bull. Insectol. 56: 51-57.

Michener, C. D. 2000. The bees of the world. John Hopkins University Press, Baltimore, MD.

Morse, R. A., and N. W. Calderone. 2000. The value of honey bees as pollinators of U.S. crops in 2000. Bee Culture 128: $1-15$.

National Honey Board. 2005. Honey industry and facts. National Honey Board. (http://www.honey.com/media/presskit/industry.asp).

[OECD] Organization for Economic Cooperation and Development. 1999. Organization for Economic Cooperation and Development Principles of Good Laboratory Practice (OECD Series on Principles of Good Laboratory Practice and Compliance Monitoring, Number 1), ENV/ MC/CHEM (98) 17.

Ohkawara, Y., A. Akayama, K. Matsuda, and W. Andersch. 2002. Clothianidin: a novel broad-spectrum neonicotinoid insecticide. Brighton Crop Proc. Conf. Pests Dis. 1: $51-58$.

[OMAF] Ontario Ministry of Agriculture and Food. 2004. Ontario Ministry of Agriculture and Food Vegetable Production Recommendations, 2004-2005. Publication 363 Queen's Printer for Ontario, Toronto, Ontario, Canada.

Roubik, D. W. [ed.]. 1995. Pollination of cultivated plants in the tropics. Food and Agriculture Organization Services Bulletin, Rome, Italy.

SAS Institute. 2006. JMP Statistical Discovery, release 6.0.2 SAS Institute, Cary, NC.

Schmuck, R. 2004. Effects of a chronic dietary exposure of the honey bee Apis mellifera (Hymenoptera: Apidae) to imidacloprid. Arch. Environ. Contam. Toxicol. 47: 471478.

Schmuck, R., and J. Keppler. 2003. Clothianidin: ecotoxicological profile and risk assessment. Pflanzenschutz.Nachr. Bayer 56: 26-58.

Schmuck, R., R. Schoening, A. Stork, and O. Schramel. 2001. Risk posed to honeybees (Apis mellifera L., Hymenoptera) by an imidacloprid seed dressing of sunflowers. Pest Manag. Sci. 57: 225-238

Schwarz, M., D. Christie, W. Andersch, K. Kemper, K. Fellmann, and R. Altmann. 2002. Control of corn rootworms (Dibrotica spp.) and secondary pests of corn (Zea mays) using seed treatments of clothianidin. Brighton Crop Prot. Conf. Pests Dis. 1: 59-64.

Smith, M. V. 1963. The O.A.C. Pollen Trap. Can. Bee J. 74 $4-5,8$.

Suchail, S., D. Guez, and L. P. Belzunces. 2001. Discrepancy between acute and chronic toxicity induced by imidacloprid and its metabolites in Apis mellifera. Environ. Toxicol. Chem. 20: 2482-2486.

Received 11 November 2006; accepted 30 January 2007. 